\title{
Civil War and the Social Contract
}

by

\author{
Jean-Paul Azama,b and Alice Mesnarda
}

a : ARQADE, University of Toulouse

b : IDEI, Institut Universitaire de France, and CSAE, Oxford.

\begin{abstract}
In this contract-theoretic model the government promises a transfer to its potential opponent in return for not engaging in a civil war. Two causes of civil war are identified. First, imperfect credibility increases the cost of the required transfer, and may make it unfeasible. Second, asymmetric information faces the government with the classic trade off between efficiency and rent-extraction, and civil war is used as a screening device. However, the latter problem can be solved by creating a mixed army, at a cost. The model determines also whether a military regime or a redistributive state prevails in a peaceful equilibrium. A statistical illustration is presented, using A frican data.
\end{abstract}

\section{Paper prepared for the R oyal Economic Society Conference, Durham, 9-11 April 2001.}

Corresponding author: Jean-Paul Azam

ARQADE, University of Toulouse,

21 Allée de Brienne, 31000 Toulouse, France,

e-mail : azam@univ-tlsel.fr 
While political violence is tearing the A frican continent apart, where most of the new civil wars break out since the end of the cold war, the economic analysis of conflicts has made significant progress during the 1990s. It offers a series of theoretical models, with some econometric application, that enhance our understanding of the rationality of the agents involved, within a deficient institutional framework. In particular, the role of ethnic division, often presented as the main determinant of civil wars has been downplayed by many papers, and in particular by Collier and Hoeffler (1998). Many ethnically divided societies avoid internal strife, and the organisation of groups along ethnic lines is seen more as a determinant of the pattern of the conflicts than as a cause of their breakout. Nowadays, the emphasis is put on the economic determinants, and on the deficient organisation of the state.

Grossman (1991) is the basic reference in this literature, analysing the problem of a government choosing the level of its military expenditures for reducing the probability of being overthrown by an insurrection. Kuran (1989) provides a complementary analysis, looking at the free-rider problem involved in organising an insurrection. Skaperdas (1992), Hirshleifer (1995) and Grossman and Kim (1995) analyse the properties of the conflict technology and their consequences for the equilibrium of the model. A synthesis of this literature, with a comparison with 'rent-seeking' models, is presented by Neary (1997). A tension in this literature is brought out by Skaperdas (1992) who points out that the occurrence of the conflict is not really explained, as the contending parties could agree beforehand to share the resources according to the expected values of their takes from the fight. In these models, the contenders are indifferent between fighting and sharing the resources peacefully. The contract-theoretic framework presented below deals with this issue, by discussing some implementation problems that may result in a war.

A new perspective is open by Azam (1995) showing that the ruling party does not need to rely exclusively on defence for staying in power, but can combine a policy of redistribution in favour of its opponent with military deterrence, thereby reducing the incentive to rebel. Azam et al. (1996) perform an econometric test of the effect of public expenditures with a strong redistributive content, like education and health, on the 
probability of the outbreak of political violence. This line of analysis is pushed further in Azam (2001), who brings out the role of the imperfect credibility of the government's commitment to redistribute in causing war, and gives examples taken from sub-Saharan Africa. In the same vein, Acemoglu and Robinson (2000) argue that the extension of the franchise in the West during the 19th century was a commitment device used by the rulers to prevent a revolution. However, this argument cannot be used in many developing countries, and in particular in sub-Saharan Africa, where social classes do not matter much, whereas ethnic rival ry is tantamount. There, many examples suggest that majority rule may lead to a dictatorship in favour of one ethnic group, oppressing the others and threatening civil peace. Azam (2001) discusses various commitment devices used by African governments.

The model presented here belongs to this line of research, and emphasises the part played by the government's ability to commit credibly to its announced redistributive expenditures in determining whether war or peace will prevail in equilibrium. It is couched in contract-theoretic terms, and brings out two different causes of war, related either to commitment failure or to asymmetric information. The former is captured by a notion of imperfect commitment, described by the probability of the government keeping its word. The model also determines endogenously what type of political system, either a military regime or a redistributive state, will prevail in a peaceful equilibrium. Beside this case where the government cannot afford a social contract ensuring peace, because of the commitment failure just described, this paper also discusses the problems raised by asymmetric information about the fighting efficiency of the potential rebels relative to the government's troupes. The government will sometimes run the risk of civil war, as a screening device. A simple extension of this model shows how this screening could instead be performed by forming a mixed army, requiring the potential rebels to contribute to peacetime defence expenditures, but this costs more than a pooling contract.

The model is presented in section 1, while the commitment problems are discussed in section 2. Section 3 is devoted to asymmetric information, and section 4 presents the case for a mixed army. A glance is given at some A frican data in section 5 in order to gauge the 
relevance of this framework for explaining simultaneously the occurrence of civil wars and the type of political systems prevailing in peaceful countries.

\section{The M odel}

There are two groups, indexed by $G$ and $E$, for government and excluded, respectively. We neglect the collective action problems that might prevent the formation of such groups in the real world, or affect their behaviour (see Kuran, 1989 and Noh,1999), assuming that each group behaves as a unitary agent. The forces that they engage in the conflict are denoted $F_{G} \geq 0$ and $F_{E} \geq 0$, respectively. The conflict technology is described by the probability $p$ of the government being overthrown by the rebels, determined as follows:

- $p=1$, if $\mu F_{E} \geq F_{G}$ and $F_{G}<\omega$,

- $p=\psi, 0<\psi<1$, if $\mu F_{E} \geq F_{G} \geq \omega$,

- $p=0$, if $\mu F_{E}<F_{G}$.

The parameter $\mu$ represents the fighting efficiency of the rebel troupes relative to the governmental ones. This may reflect both the warfare technology, more or less favourable to the government or the guerrilla, and more ideological weapons, like the degree of political mobilisation or the morale of the army or of the rebellion troupes. We take this as exogenous, although Herbst (2000) has recently produced an illuminating political analysis of the means used by guerrilla leaders to enhance this efficiency, in Africa. The parameter $\omega$ captures a scale effect in the defence technology of the government, such that a minimum level of defence expenditures is required, to avoid being ousted by any odd challenge otherwise.

Given this warfare technology, the government can either fight with the excluded group, or pay the price of peace, i.e. give away to the potential rebels a transfer equivalent to the expected value of their catch in case of war (Azam, 2001). Skaperdas (1992) notes that a transfer could settle the dispute by giving each contender the expected value of his take 
from the conflict, but this raises some implementation problems, for building the right institutional framework for a peaceful state, which are the focus of the present paper.

The game takes place in three stages :

(i) The government engages $F_{G}$ and offers to the excluded group the following contract: 'I give you $\mathrm{g} \geq 0$ if you choose $F_{E}<\frac{F_{G}}{\mu}$. However, because of the imperfect commitment technology available to the government, it is known that the transfer $\mathrm{g}$ will only be effected with probability $\lambda$, which measures the credibility of the government.

(ii) The excluded group chooses its forces $F_{E}$ and the conflict takes place if $F_{E} \geq \frac{F_{G}}{\mu}$.

(iii) The transfer $g$ is delivered with probability $\lambda$ if the conflict was avoided, and the players get the payoffs described below.

The expected utility of the government is :

$$
U_{G}=(1-p)\left(y_{G}-\gamma F_{G}-\lambda g\right),
$$

where $\gamma>1$ reflects the cost of running an army, assumed higher than its opportunity cost, because of the negative externality that it may entail (disruption of economic activity, uncontrolled violence, etc.), and $y_{G}>\gamma \omega$ is the exogenous endowment of the government, capturing all the taxes, levies, and royalties that the government collects. The government faces the following budget constraint :

$$
y_{G}-\gamma F_{G}-g \geq 0
$$

Knowing that $\mathrm{pg}=0$, and denoting $\mathrm{y}_{\mathrm{E}}$ the exogenous endowment of the excluded group, the expected utility of the latter is :

$$
U_{E}=y_{E}-F_{E}+\lambda g+p\left(y_{G}-\gamma F_{G}-\lambda g\right) .
$$

This formulation captures clearly the stakes of the civil war, namely the transfer with probability $p$ of the remaining resources of the government to the excluded group. 
Definitions 1 : Denoting $F_{E}^{W}$ and $F_{E}^{P}$, as the excluded group's forces in case of war and peace, respectively, and $p^{W}=1$ if $\mathrm{F}_{\mathrm{G}}<\omega$ and $p^{W}=\psi$ if $\mathrm{F}_{\mathrm{G}} \geq \omega$, define

(i) the peace dividend as $\lambda g+F_{E}^{W}$; and

(ii) the return to war as $p^{W}\left(y_{G}-\gamma F_{G}\right)$.

The former is the sum of the expected transfer and the cost of conflict saved by not waging the war, while the latter is the expected value of the take from the government in case of war. We can now prove the following:

Proposition 1: (i) the excluded group accepts the social contract, with $F_{E}^{P}=0$, if the following participation constraint holds :

$$
\lambda g+F_{E}^{W} \geq p^{W}\left(y_{G}-\gamma F_{G}\right)
$$

i.e. if the peace dividend is at least as large as the return to war ;

(ii) it wages the war, with $F_{E}^{W}=\frac{F_{G}}{\mu}$ otherwise.

Proof : In case of peace, the excluded group seeks to

$$
\max U_{E}^{P}=y_{E}-F_{E}^{P}+\lambda g \quad \text { s.t. } 0 \leq F_{E}^{P}<\frac{F_{G}}{\mu},
$$

entailing $F_{E}^{P}=0$, and in case of war, it seeks to :

$$
\max U_{E}^{W}=y_{E}-F_{E}^{W}+p^{W}\left(y_{G}-\gamma F_{G}\right) \text { s.t. } F_{E}^{W} \geq \frac{F_{G}}{\mu},
$$

entailing $F_{E}^{W}=\frac{F_{G}}{\mu}$. Then, $U_{E}^{P} \geq U_{E}^{W}$ implies (7). Q ED

Condition (7) means that peace must give the excluded group at least as much as the expected value of what it could capture by war, if the former is to be chosen. It also hints at the social gain from peace, namely the resources saved from being engaged in the war by the excluded group. It also shows that the government faces a trade off between promising more transfer or increasing its defence expenditures as a way to deter rebellion. The larger the forces engaged by the government, the lower the expected value of the transfer required to fulfil this constraint, which is represented at figure 1, after substituting from (ii) into (7). 
In order to proceed further, we need the following lemma :

Proposition 2 : The government chooses $F_{G} \geq \omega$ in all cases.

\section{Proof : See appendix.}

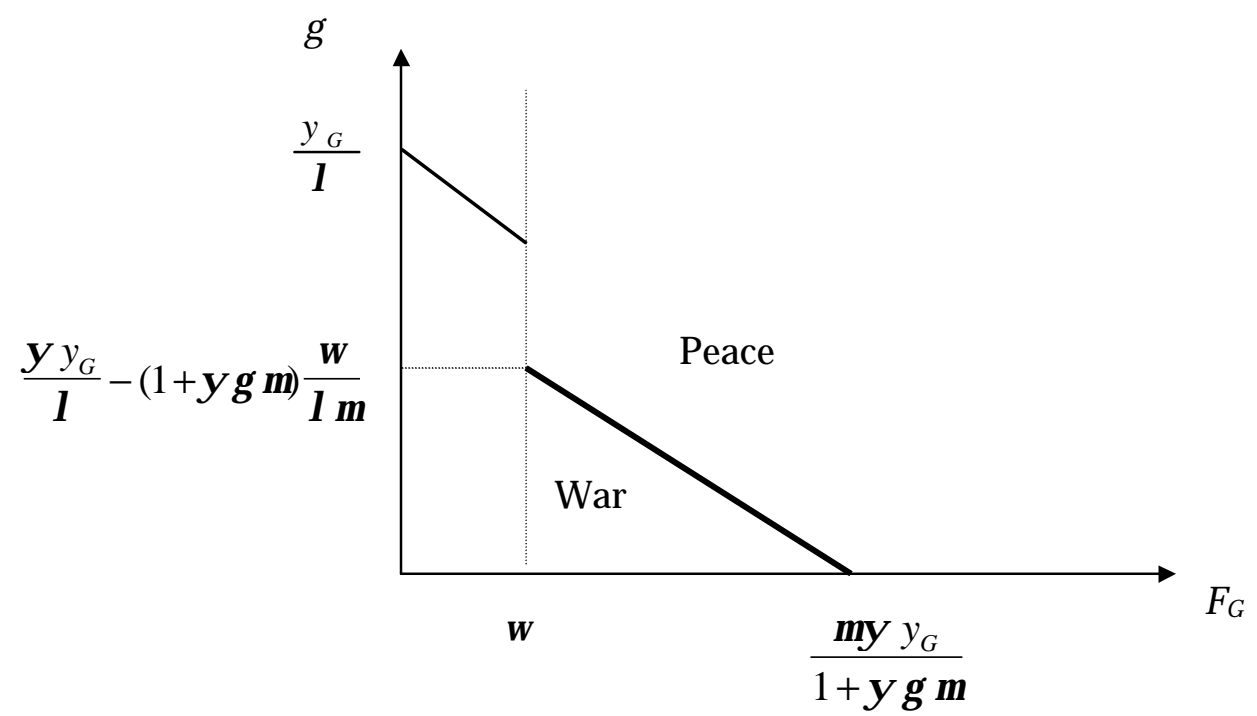

Figure 1

The intuition for proposition 2 is straightforward: if the government does not engage at least this minimum level of forces, then its expected gain is zero, while if it does, the budget constraint ensures that the remaining resources are non negative.

\section{Commitment Failure}

In this section, we analyse how the imperfect credibility of the government promise to redistribute part of its resources can lead to a civil war.

Definitions 2 : (i) A feasible social contract is a pair $\left\{g, F_{G}\right\}$ such that both the participation constraint (7) and the budget constraint (5) hold simultaneously. This requires:

$$
\lambda \geq \psi-\frac{F_{G}}{\mu\left(y_{G}-\gamma F_{G}\right)} .
$$

(ii) A social contract is desirable for the government if : 


$$
(1-\psi)\left(y_{G}-\gamma F_{G}\right)+\frac{F_{G}}{\mu} \geq(1-\psi)\left(y_{G}-\gamma \omega\right) .
$$

Notice that (8) is trivially satisfied if $\lambda \geq \psi$. Credibility problems may thus arise when the probability of toppling the government by a civil war is higher than the probability of the government keeping its promise of a transfer. Then, the government must compensate this credibility gap by increasing its defence expenditures, for reducing the return to war. The left-hand side of (9) is the expected resources left to the government after promising the minimum transfer required to ensure peace, while the right-hand side is the expected resources left in case of war. This condition holds trivially if $1 \geq \mu \gamma(1-\psi)$. Otherwise, it requires :

$$
F_{G} \leq \frac{\mu \gamma(1-\psi) \omega}{\mu \gamma(1-\psi)-1} .
$$

Condition (10) gives the maximum value that the government is prepared to invest in defence, when $\mu$ is relatively large. Beyond that level, it is cheaper to go for a war. Define $F_{\text {GMax }}$ as the right-hand side of condition (10), noticing that it is always larger than $\omega$.

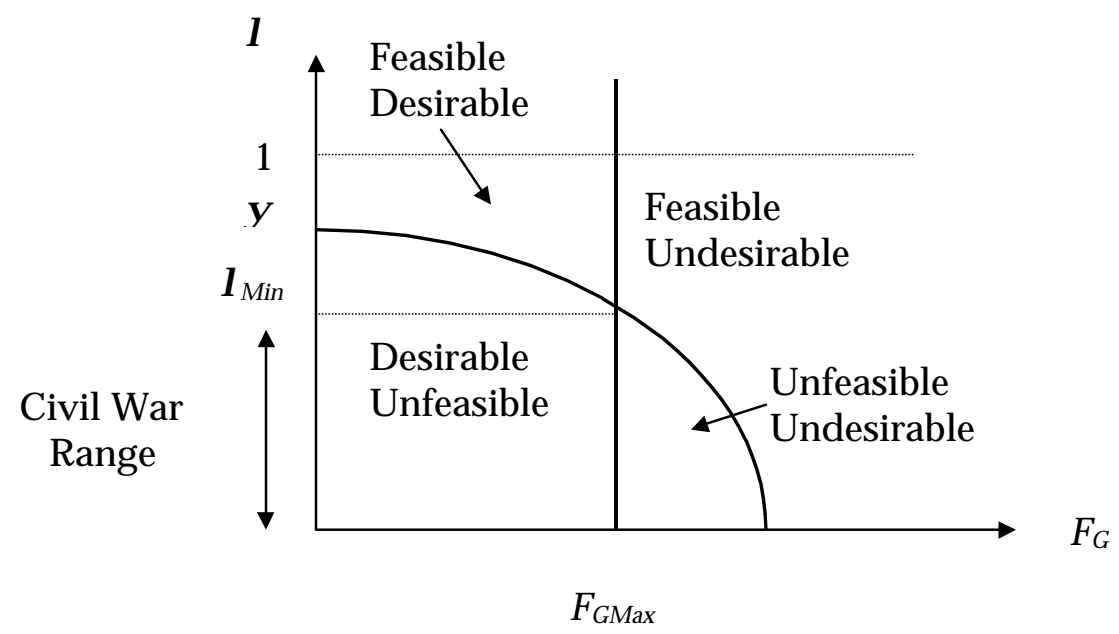

\section{Figure 2}

These conditions determine jointly the opportunity set within which the government chooses the social contract offered. It might be empty for some values of the parameters. In this case, civil war is the only option left. Figure 2 depicts a case where, given $F_{\text {GMax }}$ and the other parameters, there exists a range of values of $\lambda<\lambda_{\mathrm{M} \text { in }}$ such that there is no social 
contract that is both feasible and desirable. The downward sloping curve is the feasibility frontier, i.e. the minimum value of $\lambda$ such that (8) holds. The vertical line represents the maximum value of $F_{G}$ such that desirable contracts exist, i.e. such that (10) holds. These curves partition this space in four zones, corresponding to social contracts that are feasible (above the feasibility frontier) or not, or desirable (to the left of $F_{G M i n}$ ) or not. Their intersection determines $\lambda_{\mathrm{M} \text { in }}$, below which a civil war breaks out, as no feasible social contract is then desirable for the government. This result may be stated formally as :

Proposition 3 : If $\mu>\frac{1}{\gamma(1-\psi)}$, the civil war breaks out if :

$$
\lambda<\lambda_{\text {Min }}=\psi-\frac{F_{G M a x}}{\mu\left(y_{G}-\gamma F_{G M a x}\right)} .
$$

Peace prevails otherwise.

Proof : Conditions (8) and (10) must hold jointly in order for peace to be chosen by the government, while (11) makes this impossible. If $1 \geq \mu \gamma(1-\psi)$ the social contract is always desirable to the government. Q ED

The intuition for this result is that low credibility makes the level of transfer required for peace very costly to the government, inducing the latter to move along the trade off identified at figure 1, and rely on higher defence expenditures. Beyond a point, the latter become more costly than accepting the risk of a civil war. Otherwise, when the credibility of the government makes the set of feasible and desirable contracts non empty, it will choose either $F_{G}=\omega$, or the point on the feasibility frontier corresponding to the given value of $\lambda$, whichever is the largest. This strategy minimises the cost of maintaining peace.

Definitions 3 : (i) a redistributive state is a government that chooses $F_{G}=\omega$, thus relying mainly on redistribution, and (ii) a military regime is a government relying on a higher level of defence expenditures for deterring rebellion. 
We can now characterise further the set of social contracts prevailing in peaceful equilibria as follows :

Proposition 4 : (i) A redistributive state is in operation if $\lambda>\lambda_{\operatorname{Min}}$ and $\mu>\frac{1}{\gamma(1-\psi)}$;

(ii) a military regime prevails if either:
(a) $\lambda=\lambda_{\text {Min }} \geq 0$ and $\mu>\frac{1}{\gamma(1-\psi)}$, then $F_{G}=\frac{(\psi-\lambda) \mu y_{G}}{1+(\psi-\lambda) \mu \gamma}$, or
(b) $\mu<\frac{1}{\gamma(1-\psi)}$, in which case $F_{G}=\frac{\mu \psi y_{G}}{1+\psi \gamma \mu}$ and $g=0$, or
(c) $\mu=\frac{1}{\gamma(1-\psi)}$, in which case $F_{G} \in\left[\omega, \frac{\mu \psi y_{G}}{1+\psi \gamma \mu}\right]$.

Proof : In case of peace, if $\lambda>\lambda_{M}$ in the government solves :

$$
\min _{g, F_{G}} \lambda g+\gamma F_{G} \quad \text { s.t. } \quad \lambda g \geq \psi\left(y_{G}-\gamma F_{G}\right)-\frac{F_{G}}{\mu}
$$

Then (i) and (ii.b) and (ii.c) follow immediately, knowing proposition 2. Case (ii.a) follows from the discussion above, as condition (8) holds in this case with equality. QED

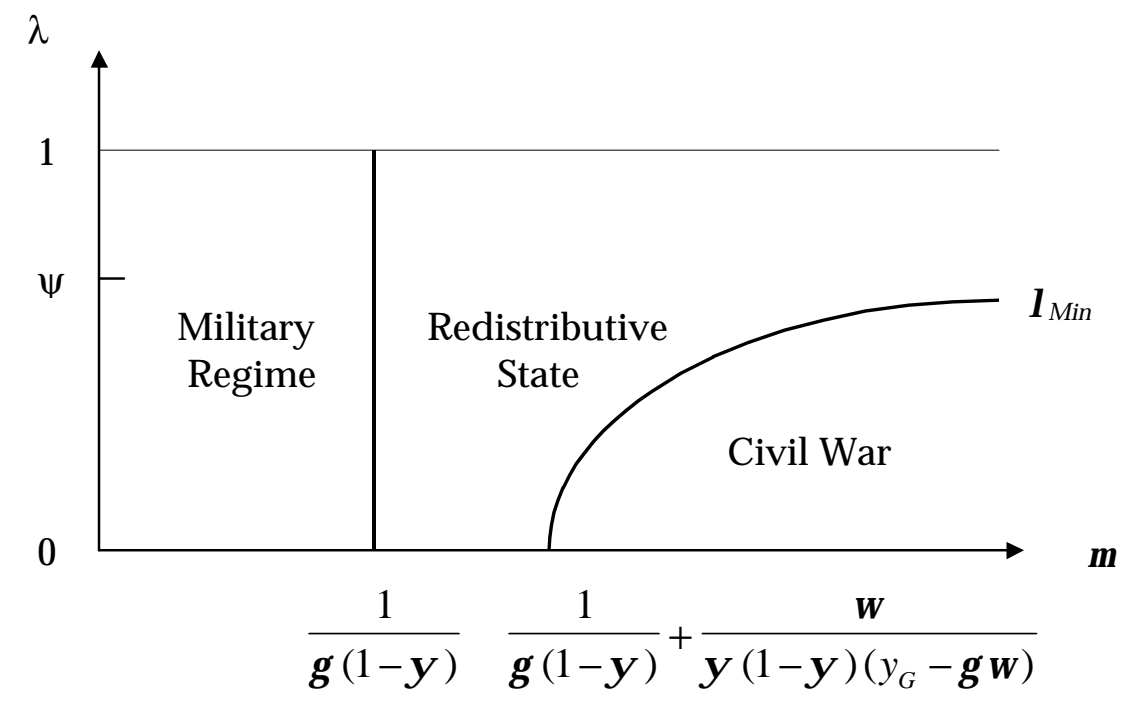

Figure 3

Figure 4 summarises this proposition, by partitioning the $(\lambda, \mu)$ space. The upward sloping curve represents the $\lambda_{m \text { in }}$ frontier, along which we have a military regime corresponding to case (ii.a). Above it, the government has enough credibility to maintain 
peace by offering the social contract described above. Below it, the government cannot afford this, and the civil war breaks out. The vertical line represents the borderline between the set of $\{\lambda, \mu\}$ pairs for which a military regime prevails and the redistributive state zone, corresponding to case (ii.c). To its left, we have a military regime proper, corresponding to case (ii.b), without any redistribution at all $(g=0)$. In all the other cases of peaceful equilibria, some redistribution occurs, in order to fulfil the excluded group's participation constraint.

We now extend the model to deal with asymmetric information problems, providing another cause of civil war.

\section{A symmetric Information}

We now assume away the problems raised by the imperfect credibility of the government's promise of a transfer. We focus instead on asymmetric information, by assuming that the excluded group can have either a high or a low fighting efficiency relative to the government's forces. At stage 1 of the game, the excluded group knows its own type, $\mu \in\left\{\mu_{H}, \mu_{L}\right\}, \mu_{H}>\mu_{L}$, while the government only knows its probability distribution, such that $\mu=\mu_{H}$ with probability $\pi$, assumed different from 0 or 1 . We can think of $\mu_{H}-\mu_{L}$ as a measure of the government ignorance, or in a more dynamic way as a positive shock affecting the relative fighting efficiency of the excluding group, treating $\mu_{L}$ as the normal state of affairs, and $\mu_{H}$ as the result of a positive shock occurring with probability $\pi$. We refer to $\mu_{H}-\mu_{L}$ as the $\mu$-shock. Having assumed away any commitment problem, we know from the previous section that the government would rather avoid war in all cases, if it knew the excluded group's type. However, because of asymmetric information, the government faces now the classic trade off between rent extraction and efficiency arising in adverse selection problems (see e.g. Salanié, 1997). In order to bring this out, define for each type the excluded group's rent as the difference between the peace dividend and the return to war : 


$$
\begin{aligned}
& R_{L}=\lambda g_{L}+\frac{F_{G}}{\mu_{L}}-\psi\left(y_{G}-\gamma F_{G}\right), \text { and } \\
& R_{H}=\lambda g_{H}+\frac{F_{G}}{\mu_{H}}-\psi\left(y_{G}-\gamma F_{G}\right) .
\end{aligned}
$$

Hence, the additional rent that the L-type group can get above that of the $\mathrm{H}$-type is :

$$
R_{L}-R_{H}=\lambda\left(g_{L}-g_{H}\right)+F_{G}\left(\frac{\mu_{H}-\mu_{L}}{\mu_{H} \mu_{L}}\right) .
$$

The second term on the right-hand side is positive by definition. The sign of the first one is found by looking at the incentive constraints for a truthful revelation mechanism. They can be written in terms of peace dividends as :

$$
\begin{aligned}
& \lambda g_{L}+\frac{F_{G}}{\mu_{L}} \geq \lambda g_{H}+\frac{F_{G}}{\mu_{L}}, \text { and } \\
& \lambda g_{H}+\frac{F_{G}}{\mu_{H}} \geq \lambda g_{L}+\frac{F_{G}}{\mu_{H}} .
\end{aligned}
$$

These conditions say that the offer made to a group of one type must give it at least as high a peace dividend as if it claimed to be of the other type. They can only hold simultaneously if $g_{L}=g_{H}$. Hence, the government is unable to screen the excluded groups according to their type by peaceful means. This implies that, if it chooses to offer an acceptable social contract to both types, then the latter must be the same for both types, and yield $R_{H}=0$ and $R_{L}=F_{G}\left(\frac{\mu_{H}-\mu_{L}}{\mu_{H} \mu_{L}}\right)$. Giving away such a rent to the L-type group is costly, and there are cases, identified in the following proposition, where the government would rather run the risk of a war against the $\mathrm{H}$-type, provided this enabled it to extract all the rent from the L-type group. Then, civil war works as a screening device.

Proposition 5 : Faced with the screening problem analysed here, the government chooses the separating equilibrium, thus accepting the risk of war (ROW) with the probability $\pi$, in the cases described in table 1. 
Table 1 : Risk of War (ROW) with Probability $\pi$

\begin{tabular}{|c|c|c|}
\hline & $\mu_{L}<\frac{1-\pi}{\gamma(1-\psi)}$ & $\frac{1-\pi}{\gamma(1-\psi)}<\mu_{L}$ \\
\hline$\mu_{H}<\frac{1}{\gamma(1-\psi)}$ & ROW if $\pi \leq \frac{\gamma\left(\mu_{H}-\mu_{L}\right)}{1+\psi \gamma \mu_{H}}$ & No ROW \\
\hline$\frac{1}{\gamma(1-\psi)}<\mu_{H}$ & ROW in all cases & ROW if $\pi \leq \frac{\mu_{H}-\mu_{L}}{\mu_{H}}$ \\
\hline
\end{tabular}

Proof : See appendix.

The intuition for these results is as follows. Given the size of the $\mu$-shock, the government will choose the pooling equilibrium, i.e. give away the informational rent to the L-type group, if the probability of the $\mu$-shock is high, while it will prefer the separating equilibrium, thus accepting the risk of war, if this probability is low. Similarly, given the probability of the $\mu$-shock, the government will choose to accommodate it, in a pooling equilibrium, if it is small, entailing the gift of a small rent to the L-type group. On the contrary, if the $\mu$-shock is large enough, the government will rather take a chance than give away such a large rent. In the diagonal cells of table 1, this risk is accepted when the probability of the $\mu$-shock is small relative to its size, as explained above. In the north-east cell of the table, the government accommodates the $\mu$-shock because its probability is necessarily large relative to its size, as we have then $\frac{1-\pi}{\gamma(1-\psi)}<\mu_{L}<\mu_{H}<\frac{1}{\gamma(1-\psi)}$. In the south-west cell of the table, we have the opposite case, where the probability of the $\mu$-shock is necessarily small relative to its size, by a symmetric argument.

\section{A Case for a Mixed Army?}

We now analyse the potential for screening the excluded group by creating a mixed army in peacetime, to which the potential rebels are required to contribute. Denote $A_{L}$ and $A_{H}$ the resources so recruited. Now, the excluded group is offered a choice between two contracts : 'I give you either $g_{L}$ if you contribute $A_{L}$ to my army, or $g_{H}$ if you contribute $A_{H}$, and do not trigger a civil war subsequently in either case'. Assume that the recruitment of 
soldiers from the excluded group in peacetime entails a positive externality, such that their relative fighting efficiency is enhanced by their participation in the governmental army. More precisely, assume:

$$
\mu_{L}=v_{L}+\alpha A_{L} \text { and } \mu_{H}=v_{H}+\alpha A_{H} \text {, with } v_{L} \leq v_{H} \text { and } \alpha>0 \text {. }
$$

Let $F_{G}$ denote the army left to the government in case of war, when the additional soldiers go back to their side. Then, the incentive constraints for a truthful revelation mechanism become:

$$
\begin{aligned}
& \lambda g_{L}+\frac{F_{G}}{\mu_{L}}-A_{L} \geq \lambda g_{H}+\frac{F_{G}}{\mu_{L}}-A_{H}, \text { and } \\
& \lambda g_{H}+\frac{F_{G}}{\mu_{H}}-A_{H} \geq \lambda g_{L}+\frac{F_{G}}{\mu_{H}}-A_{L} .
\end{aligned}
$$

They jointly imply :

$$
\lambda g_{L}-A_{L}=\lambda g_{H}-A_{H}
$$

The rents of the two types now become:

$$
\begin{aligned}
& R_{L}=\lambda g_{L}-A_{L}+\frac{F_{G}}{\mu_{L}}-\psi\left(y_{G}-\gamma F_{G}\right), \text { and } \\
& R_{H}=\lambda g_{H}-A_{H}+\frac{F_{G}}{\mu_{H}}-\psi\left(y_{G}-\gamma F_{G}\right) .
\end{aligned}
$$

A separating outcome with full rent extraction is now possible, and a necessary condition for this, with $R_{L}=R_{H}=0$, is:

$$
\mu_{L}=\mu_{H} .
$$

Condition (23) brings out the effect of the recruitment of soldiers from the excluded group in the governmental army : it reduces the government's uncertainty by making the two types 'alike', with a common $\mu$. This requires a larger recruitment of soldiers from- and a larger promised transfer to- the L-type, as combining (17), (20) and (23) yields :

$$
A_{L}=A_{H}+\frac{v_{H}-v_{L}}{\alpha} \text {, and }
$$




$$
g_{L}=g_{H}+\frac{v_{H}-v_{L}}{\lambda \alpha}
$$

Assume that the soldiers so recruited yield to the government a marginal utility $0 \leq$ $\omega<1$, to reflect the social cost of taking them away from production. We can now state:

Proposition 6 : (i) The cheapest separating contract avoiding war by requiring the excluded groups to contribute to the peacetime defence expenditures is such that (23), (24) and (25) hold, with $\mathrm{A}_{H}=0$ and $g_{H}=\frac{\psi}{\lambda}\left(y_{G}-\gamma F_{G}\right)-\frac{F_{G}}{\lambda \mu}$;

(ii) it is more costly to the government than the pooling contract of section 3.

Proof : The government solves:

$$
\begin{array}{ll}
\min _{g_{H}, g_{L}} \pi\left(\lambda g_{H}-\omega A_{H}\right)+(1-\pi)\left(\lambda g_{L}-\omega A_{L}\right)+\gamma F_{G}, \\
\text { s.t. } \lambda g_{H} \geq A_{H}+\psi\left(y_{G}-\gamma F_{G}\right)-\frac{F_{G}}{\mu_{H}}, \text { with } A_{H} \geq 0, A_{L} \geq 0 \text {, and (20), and } \\
& \lambda g_{L} \geq A_{L}+\psi\left(y_{G}-\gamma F_{G}\right)-\frac{F_{G}}{\mu_{L}} .
\end{array}
$$

This yields (23), (24), (25) and proposition 6 (i), if (26) is binding. The $\mathrm{H}$-group gets the same transfer as in the pooling contract of section 3, and the L-group a larger one. The net expected loss is $(1-\pi)(1-\omega) \frac{\mathrm{v}_{H}-\mathrm{v}_{L}}{\alpha}$. Q ED

A similar argument could be made by assuming $\alpha<0$, for capturing a hostage effect. Then the L-type would get as much as in the pooling contract, and the $\mathrm{H}$-type more.

\section{A G lance at Some African D ata}

Brunetti et al. (1998) have produced some data on the credibility of the government, based on a survey of a large number of firms in many countries performed in 1996-97. We use as our credibility indicator the average answer to the question: 'do you expect the government to stick to announced major policies ?', coded so that the highest credibility scores six, and the lowest one1. We have restricted the sample to African countries, because this is where civil wars are the most pressing issue. As suggested by Collier and Hoeffler

\footnotetext{
${ }^{1}$ Data taken from Béatrice Weder's web site.
} 
(1998), ethno-linguistic fractionalisation (ELF) is an impediment to the organisation of a successful insurrection, and we take one minus ELF as our indicator of the relative fighting efficiency of the excluded group2. This should be regarded as a very rough proxy, as it does not take into account the access to external support, the supplies of weaponry, etc. Then, we have tentatively classified the sample countries as described in table 2 . We regard as military regimes the countries not at war with the highest share of military expenditures in the central government budget, plus Nigeria, which was a military regime until recently. Some of these classifications are disputable: Mali had a peripheral war in the north in 1990-93, while in Zimbabwe, the political violence of the 1990s is not officially recognised as a civil war. Côte d'Ivoire, for which the data on military expenditures is missing, could have been classified as a military regime, because French troupes are located near Abidjan, and a coup took place in 1999, putting a General in power for about a year.

\section{Table 2 : Country Classification}

\begin{tabular}{|c|c|c|}
\hline Military Regime & War in the 1990s & Others: \\
\hline m7 =Zambia : 2.8 & w1 = Chad : 3.1 & B = Bénin : 1.2 \\
\hline $\mathrm{m} 2=$ Kenya $: 2.3$ & $w 2=$ Congo $: 2.9$ & $\mathrm{Cl}=$ Côte d'Ivoire : na \\
\hline $\mathrm{m} 6=$ Togo $: 2.3$ & w3 = Mozambique : 5.4 & Gh = Ghana $: 1.4$ \\
\hline m1 = Cameroon : 1.9 & w4 = Uganda : 2.3 & Gu = Guinea : 1.5 \\
\hline m5 =Tanzania : 1.8 & w5 =Zimbabwe : 4 & Mad = Madagascar : 0.9 \\
\hline $\mathrm{m} 3=$ Mali : 1.8 & & Mw = Malawi : 1.6 \\
\hline $\mathrm{m} 4=\mathrm{N}$ igeria $: 0.8$ & & Ms $=$ Mauritius : 0.4 \\
\hline & & $\mathrm{S}=$ Senegal $: 1.6$ \\
\hline
\end{tabular}

N ote : Share of military expenditures in central government budget (from WDI 1999) beside the country's name.

Figure 4 presents the results of this classification, in the \{credibility/fighting efficiency s space. The military regimes are grouped in the left-hand part of the chart, as predicted by the model. The countries at war are located in the lower half of the credibility

\footnotetext{
${ }^{2}$ Data taken from Bob Bates's web site.
} 
range, as predicted, but not necessarily among the most efficient ones. Hence, some lowprobability $\mu$-shocks might have occurred here, especially in Chad and Uganda. Madagascar was omitted as an outlier. It would be predicted to be at war, being located in the southeastern part of the space, while it was not. However, the Ratsiraka government was overthrown in 1991 by a non violent popular uprising, beside the massacre of protesters in August 1991. Therefore, despite some plausible omitted variable bias, our theoretical predictions shed some light on these recent African data.

Credibility

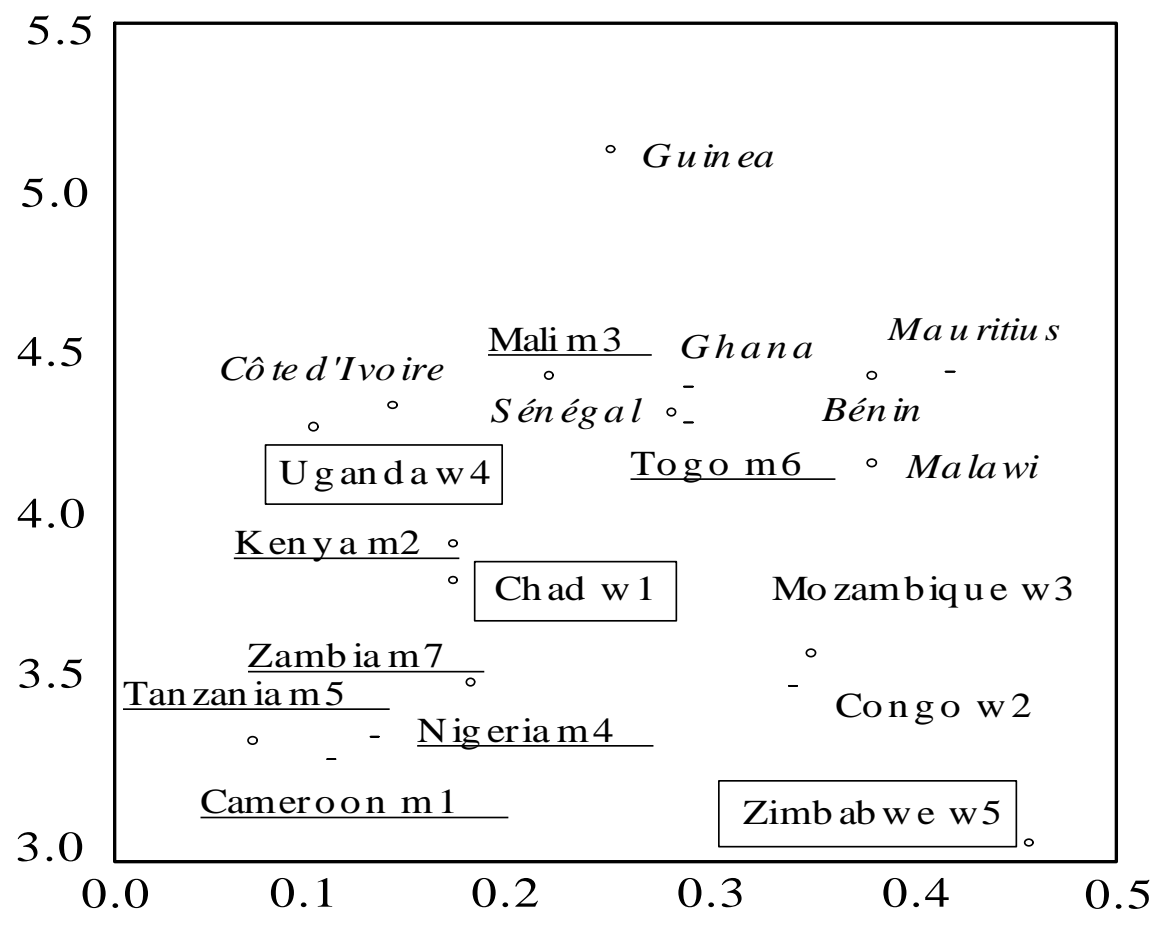

Fighting Efficiency (1 minus ethno-lingu istic Figure 4 fraction alisation)

\section{Conclusion}

We have identified two possible causes of civil war, in a contract-theoretic framework, assuming that two groups are facing each other, without any collective action problem. The conflict technology allows the excluded group to overthrow the one in power, with a given probability, if it puts in the fight enough resources relative to the government defence expenditures. The government engages a given level of defence expenditures at the 
initial stage, and offers a social contract promising to deliver a transfer if the excluded group refrains from rebelling.

The first possible cause is the imperfect credibility of the government. If it is known that the government will only keep its promise with a given probability, and default otherwise, then the promised transfer needs to be larger, the smaller this probability. There comes a point where the government cannot afford it and goes for a war instead. The second cause is asymmetric information, when the potential rebels are knowingly of a more or less efficient type for fighting, while the government only knows the probability distribution over these types. Then, offering a social contract that is only acceptable to the less efficient type, thus running the risk of a war if the potential rebels are of the other type, might be for the government a way of handling the trade off between efficiency and rent extraction. However, the importance of this second cause of civil war depends on the availability of alternative screening devices. Recruiting soldiers from the excluded group in the peacetime army, thereby enhancing their fighting efficiency, might be used for screening, but is more costly than not screening at all.

The lessons for a peace-keeping strategy are clear cut. It is first important to help the government enhance its credibility, and the most promising route for this is to strengthen checks and balancel, including an active civil society. Then, in order to mitigate asymmetric information problem 1 , a reliable system must be put in place for monitoring the degree of political mobilisation and military potential of the excluded group. Lastly, it might be useful to recruit and train some soldiers from the excluded group in the peacetime army, when the context makes it feasible, but the extra cost involved must be borne by a donor if it is to be accepted by the government.

\section{Appendix :}

\section{Proof of Proposition 2.}

(i) In case of war, the government seeks to:

$$
\max _{F_{G}} \quad U_{G}^{W}=\left(1-p^{W}\right)\left(y_{G}-\gamma F_{G}\right)
$$


s.t. $\quad p^{W}=1 \quad$ if $\quad F_{G}<\omega$ and $p^{W}=\psi \quad$ if $\quad F_{G} \geq \omega ;$

then it chooses $F_{G} \geq \omega$ and $p^{W}=\psi$ as $y_{G}>\gamma \omega$.

(ii) In case of peace, neglect first the budget constraint. Then, the government seeks to :

$$
\begin{array}{ll}
\max _{F_{G}} \quad U_{G}^{P}=y_{G}-\gamma F_{G}-\lambda g \\
\text { s.t. } \quad \lambda g \geq \psi\left(y_{G}-\gamma F_{G}\right)-\frac{F_{G}}{\mu} \text { if } F_{G} \geq \omega \text { and } \lambda g \geq y_{G}-\gamma F_{G}-\frac{F_{G}}{\mu} \text { if } F_{G}<\omega .
\end{array}
$$

Then, $U_{G}^{P}=(1-\psi)\left(y_{G}-\gamma F_{G}\right)+\frac{F_{G}}{\mu}$ if $F_{G} \geq \omega$ and $U_{G}^{P}=\frac{F_{G}}{\mu}$ if $F_{G}<\omega$. So, it will choose $F_{G} \geq \omega$ as $y_{G}-\gamma F_{G} \geq g \geq 0$, 
(2) $F_{G}^{2}=\omega \quad$ and $\quad g=\frac{\psi}{\lambda}\left(y_{G}-\gamma \omega\right)-\frac{\omega}{\lambda \mu_{L}} \quad$ if $\quad \mu_{L}>\frac{1-\pi}{\gamma(1-\psi)}$.

The corresponding values of its objective function are:

(1) $U_{G}^{\text {Sep } 1}=\frac{(1-\psi \pi) y_{G}}{1+\gamma \psi \mu_{L}}$, and

(2) $U_{G}^{\text {Sep } 2}=(1-\psi) y_{G}+\frac{\omega}{\mu_{L}}\left(1-\pi-(1-\psi) \gamma \mu_{L}\right)$.

Then, for each of the four possible cases, one compares the values of the objective function obtained under either choice for deriving table 1. QED

\section{References :}

Acemoglu, D. and J. Robinson (2000) : «Why Did the West Extend the Franchise? Democracy, Inequality, and Growth in Historical Perspective », Quarterly Journal of Economics, 115, 1167-99.

Azam, J.-P. (1995), « How to Pay for the Peace ? A Theoretical Framework with References to African Countries », Public Choice, 83, 173-84.

Azam J.-P. (2001) : «The Redistributive State and Conflicts in Africa », Journal of Peace Research, 38 .

Azam, J.-P., Berthélemy, J.-C., and Calipel, S. (1996) : «Risque politique et croissance en Afrique », Revue économique, 47, 819-29.

Brunetti, A., G. Kisunko, and B. Weder (1998) : «Credibility of Rules and Economic Growth : Evidence from a Worldwide Survey of the Private Sector», World Bank Economic Review, 12, 353-84.

Collier P., and Hoeffler A.E. (1998): «On Economic Causes of Civil Wars », Oxford Economic Papers, 50, 563-73.

Grossman H.I. (1991): «A General Equilibrium Model of Insurrections », American Economic Review , 81, 912-21.

Grossman H.I., and M. Kim (1995) : « Swords or Plowshares? A Theory of the Security of Claims to Property », Journal of Political Economy, 103, 1275-88. 
Herbst, J. (2000) : «Economic Incentives, Natural Resources and Conflict in Africa », Journal of African Economies, 9, 270-94.

Hirschleifer J. (1995) : «Anarchy and its Breakdown», Journal of Political Economy, 103, 26-52.

Kuran T. (1989): «Sparks and Prairie Fires: A Theory of Unanticipated Political Revolution », Public Choice, 61, 41-74.

Neary H.M. (1997) : «A Comparison of Rent-Seeking Models and Economic Models of Conflict », Public Choice, 93, 373-88.

Noh, S.J. (1999) : «A General Equilibrium Model of Two-group Conflict with Endogenous Intra-group Sharing Rules », Public Choice 98, 251-67.

Salanié, B. (1997) : Contract Theory : A Primer, MIT Press : Cambridge.

Skaperdas S. (1992), « Cooperation, Conflict, and Power in the Absence of Property Rights », American Economic Review, 82, 720-39.

WDI (1999) : World Development Indicators 1999, World Bank : Washington DC. 